\title{
RESEARCH
}

\section{The impact of physician training and experience on the survival of patients with active tuberculosis}

\author{
Kamran Khan, Ann Campbell, Tamara Wallington, Michael Gardam
}

$\infty \quad$ See related article page 759

\section{ABSTRACT}

Background: Physician training and experience may be important factors influencing treatment outcomes of patients with tuberculosis. We conducted an analysis to evaluate physician and patient characteristics and their association with the rate of death among tuberculosis patients.

Methods: We retrospectively reviewed all reported cases of active tuberculosis in Toronto between July 1, 1999, and June 30, 2002. We obtained extensive clinical data on cases as well as information on the training and clinical experience of treating physicians. We subsequently identified factors associated with patient mortality in a survival analysis.

Results: In a multivariable Cox regression analysis involving 1154 patients, factors associated with all-cause mortality included patient age (in years) (hazard ratio [HR] 1.05, 95\% confidence interval $[\mathrm{CI}] 1.04-1.07, p<0.001)$, use of directly observed therapy (HR 0.22, $\mathrm{Cl} 0.13-0.39, p<0.001)$, receipt of care from a physician experienced with tuberculosis (per case managed per year) ( $\mathrm{HR} 0.98, \mathrm{Cl} 0.97-0.99 ; p=0.01$ ) and admission to hospital during the course of treatment (HR 15.44, $\mathrm{Cl} 7.06-33.76, p<0.001)$. Factors that were not associated with patient survival included whether the physician graduated from a foreign medical school, the physician's medical specialty and the number of years in clinical practice.

Interpretation: Physician experience with tuberculosis and use of directly observed therapy positively influenced the survival of patients with active tuberculosis in our setting.

CMAJ 2006;175(7):749-53

$\mathrm{T}$ he incidence of tuberculosis is declining in many parts of the industrialized world. ${ }^{1-4}$ As this occurs, tuberculosis is largely becoming a disease of recent immigrants, refugees and other vulnerable populations..$^{1,2}$ This shift in the burden of disease to more marginalized segments of society has increased the complexity of providing quality care. Fear of immigration authorities, language and cultural barriers, financial restraints, lack of health insurance, inadequate housing and medical comorbidities such as HIV infection are important factors that frequently complicate the management of tuberculosis..$^{5-8}$ Moreover, as incidence rates decline, fewer physicians are managing active tuberculosis cases on a regular basis. This decline in clinical expertise may result in medical errors and decreased quality of care..$^{9,10}$

The association between physician experience and patient survival has been described for medically and socially complex diseases such as HIV/AIDS. ${ }^{11,12}$ In addition, studies have demonstrated the relation between surgical volume and health outcomes for a wide array of surgical procedures. ${ }^{13,14} \mathrm{Al}$ though authors of previous tuberculosis studies have identified an association between physician expertise, treatment errors and the initiation of appropriate tuberculosis therapy, ${ }^{9,10}$ no studies to date have examined the role of the physician in influencing the survival of patients with active tuberculosis.

\section{Methods}

We retrospectively reviewed all 1173 cases of active tuberculosis that were diagnosed on the basis of microbiologic or clinical criteria and reported to Toronto Public Health between July I, I999, and June 30, 2002. We excluded I9 cases that were incidentally identified after the patients had died, because our analysis was centred on the relation between physician treatment of tuberculosis and patient mortality. Specifically, none of the Ig tuberculosis cases diagnosed on autopsy was offered treatment. In total, we included II54 active tuberculosis cases in our analysis, including 34 patients who were known to be coinfected with HIV.

Patient demographic, clinical and mortality data were obtained from Toronto Public Health's reportable disease database and complemented with the organization's tuberculosis case management files. These data sources were also used to identify the treating physicians of record for reported cases and to determine the number of active tuberculosis cases managed by each physician during the study period. Data pertaining to physician's undergraduate and postgraduate medical training and years in clinical practice were obtained from the physician database of the College of Physicians and Surgeons of Ontario (www.cpso.on.ca/Doctor_Search/adv_srch .asp?SCR=FIRST).

Patient demographic data collected for the analysis included age (in years) at the time of diagnosis, sex, languages 
spoken and whether the participants were homeless. Clinical information included HIV status, admission to hospital during the course of treatment, use of directly observed therapy, primary and, when applicable, secondary sites of infection and tuberculosis drug resistance. People receiving directly observed therapy were defined as those who received home visits from public health staff at any time during the course of treatment. High-risk sites of tuberculosis were defined as those involving the cardiac or central nervous system. Infections were defined as resistant if the organism displayed resistance to any first-line tuberculosis drugs, with the exception of streptomycin. We considered cases diagnosed on the basis of clinical criteria alone to be fully sensitive.

Physician data included information on undergraduate medical training (medical school and country of graduation), postgraduate medical training (physician specialty), overall clinical experience (number of years in clinical practice) and tuberculosis-specific experience (mean number of cases treated per year during the study period). Physicians were considered tuberculosis specialists if they completed postgraduate training in respirology or infectious diseases. Moreover, we defined physicians as "tuberculosis-experienced" if they managed at least I active case per year on average, and "tuberculosis-inexperienced" if they managed fewer cases during the study period.
When more than I physician was involved in the management of a patient, the initial provider was defined as the physician of record. However, in instances where providers referred their patient on to another physician before initiating tuberculosis therapy or within I month of initial diagnosis, the receiving physician was then defined as the physician of record.

A single research coordinator collected all data using a standardized data-collection method. Data were obtained after we received approval from the research ethics boards at the University Health Network and the City of Toronto.

We compared baseline characteristics of patients with active tuberculosis across physician experience and mortality (regardless of cause) I year after the initial diagnosis. Categorical and continuous variables were compared using the Fisher's exact test and the Student's $t$ test, where appropriate. We plotted Kaplan-Meier graphs of the relation between individual predictor variables and all-cause mortality. The log-rank test was used to assess the statistical significance of these relations.

We subsequently performed multivariable Cox proportional hazards regression analyses. In cases where the patients did not die, they were censored at the end of the study's analytic horizon (i.e., I year) or on the date they were last observed. We developed our final multivariable model using stepwise selection, allowing variables to remain in the model if they were significant at the o.r level. We tested the propor-

Table 1: Baseline characteristics of 1154 patients with active tuberculosis (TB), by treating physician's experience with TB and by all-cause mortality

No. (\%) of patients*

\begin{tabular}{|c|c|c|c|c|c|c|}
\hline Characteristic & $\begin{array}{c}\text { Physician } \\
\text { experienced with } \mathrm{TB} \dagger \\
n=1027\end{array}$ & $\begin{array}{c}\text { Physician } \\
\text { inexperienced with } \mathrm{TB} \dagger \\
n=127\end{array}$ & $p$ value & $\begin{array}{c}\text { Patient } \\
\text { dead at } 1 \mathrm{yr} \\
n=85\end{array}$ & $\begin{array}{l}\text { Patient } \\
\text { alive at } 1 \mathrm{yr} \\
n=1069\end{array}$ & $p$ value \\
\hline \multicolumn{7}{|l|}{ Patients } \\
\hline Age, yr, mean (SD) & $44.4(1.3)$ & $43.9(4.0)$ & 0.81 & $68.5(4.9)$ & $42.4(1.2)$ & $<0.001$ \\
\hline Sex, male & $564(54.9)$ & $66(52.0)$ & 0.57 & $56(65.9)$ & $574(53.7)$ & 0.03 \\
\hline Language, English & $675(65.7)$ & $89(70.1)$ & 0.37 & $36(42.4)$ & $728(68.1)$ & $<0.001$ \\
\hline Homeless & $27 \quad(2.6)$ & $6 \quad(4.7)$ & 0.17 & $5 \quad(5.9)$ & $28 \quad(2.6)$ & 0.09 \\
\hline HIV infection & $27 \quad(2.6)$ & $7 \quad(5.5)$ & 0.09 & $3 \quad(3.5)$ & 31 (2.9) & 0.73 \\
\hline Admitted to hospitalf & $423(41.2)$ & $56(44.1)$ & 0.57 & $78(91.8)$ & $401(37.5)$ & $<0.001$ \\
\hline Received DOT‡ & $481(46.8)$ & $36(28.4)$ & $<0.001$ & $16(18.8)$ & $501(46.8)$ & $<0.001$ \\
\hline High-risk site of infection§ & 19 (1.9) & $5 \quad(3.9)$ & 0.17 & $6 \quad(7.1)$ & $18 \quad(1.7)$ & 0.006 \\
\hline Drug resistance (any)ף & 102 (9.9) & $5 \quad(3.9)$ & 0.02 & 3 (3.5) & $104 \quad(9.7)$ & 0.08 \\
\hline \multicolumn{7}{|l|}{ Treating physicians } \\
\hline Foreign graduate $e^{* *}$ & $300(29.2)$ & $36(28.4)$ & 0.92 & $21(24.7)$ & $315(29.5)$ & 0.39 \\
\hline TB specialist+† & $919(89.5)$ & $32(25.2)$ & $<0.001$ & $58(68.2)$ & $893(83.5)$ & $<0.001$ \\
\hline Years in practice, mean (SD) & $23.9(0.6)$ & $21.8(2.0)$ & 0.04 & $23.2(2.2)$ & $23.7(0.6)$ & 0.68 \\
\hline All-cause mortality at $1 \mathrm{yr}$ & $64 \quad(6.2)$ & $21(16.5)$ & $<0.001$ & - & - & - \\
\hline
\end{tabular}

Note: SD = standard deviation, DOT = directly observed therapy.

*Unless stated otherwise.

tExperience was defined as management of at least 1 case of active TB per year. Physicians considered to be inexperienced with TB were those who managed fewer cases per year.

$\ddagger$ At any time during the course of TB treatment.

§Site involving the cardiac or central nervous system.

ๆOrganism was resistant to first-line TB drugs except streptomycin. Clinically diagnosed cases and those with resistance to streptomycin alone were considered nonresistant.

${ }^{* *}$ Completed undergraduate medical training outside of Canada.

††Completed postgraduate training in respiratory medicine or infectious diseases. 
tional hazards assumption using graphical methods (i.e., log-log survival plots) and the timedependent covariate method; we found no evidence of violation.

\section{Results}

A total of 1154 patients managed by 178 physicians met our study criteria. The baseline characteristics of the patients according to whether their physician was experienced ( $n=1027$ ) or not experienced with tuberculosis $(n=127)$ and whether the patients were alive $(n=\mathrm{Io} 69)$ or had died at I year $(n=85)$ are shown in Table $\mathrm{I}$.

Patients in each group had similar demographic and clinical characteristics, with the following exceptions: patients managed by tuberculosis-experienced physicians were more likely than those with tuberculosis-inexperienced physicians to receive directly observed therapy $(46.8 \%$ v. $28.4 \%, p<0.00 \mathrm{I}$ ), to have drug-resistant infections $(9.9 \%$ v. $3.9 \%, p=0.02)$, to receive treatment from a physician trained in respirology or infectious diseases ( $89.5 \%$ v. $29.2 \%, p<0.00 \mathrm{I})$ and to receive treatment from a physician with more years in clinical practice (mean [standard deviation] 23.9 [0.6] v. 2I.8 [2.0], $p=0.04$ ).

Of particular note, $\mathrm{I} 6.5 \%$ of the patients managed by tuberculosis-inexperienced physicians died within I year after diagnosis, as compared with $6.2 \%$ of the patients managed by tuberculosisexperienced physicians $(p<0.001)$. When further stratified by the number of tuberculosis cases treated, $19.2 \%$ of the patients (19/99) managed by physicians with no previous tuberculosis experience during the past 3 years died within I year after diagnosis, as compared with $7.1 \%$ of the patients (3I/435) managed by physicians treating up to 5 cases per year, and $5.7 \%$ of those (35/620) managed by physicians treating more than 5 cases per year.

Of the 178 physicians managing patients with tuberculosis in our study cohort, $32.6 \%$ were family physicians, $27.0 \%$ were internists or pediatricians, $21.9 \%$ were respirology specialists, $16.3 \%$ were adult or pediatric infectious diseases specialists, and $2.3 \%$ were physicians of other medical or surgical specialties. In terms of experience with the treatment of active tuberculosis, $20.2 \%$ of the physicians had managed, on average, at least 3 cases per year, $\mathrm{I} 6.3 \%$ had managed between $\mathrm{I}$ and 3 cases per year, and $63.5 \%$ had managed fewer than I case per year during the 3 -year study period.

Kaplan-Meier plots of the association between physician experience with tuberculosis and allcause mortality, and between use of directly observed therapy and all-cause mortality, are shown in Fig. I. Overall, greater tuberculosis-specific experience was associated with improved survival at

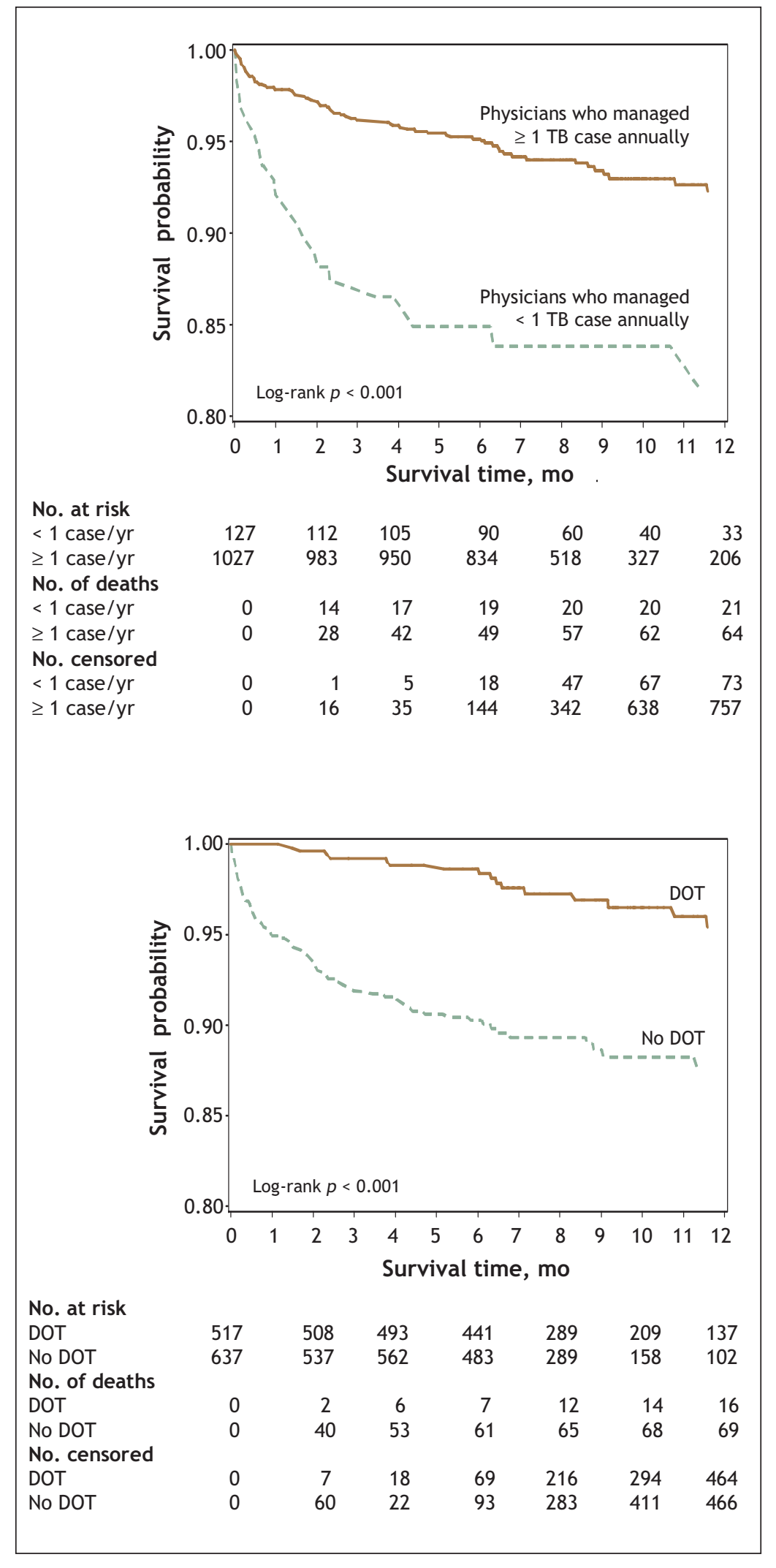

Fig. 1: Kaplan-Meier survival analyses involving 1154 patients with active tuberculosis, revealing association between physician experience with tuberculosis and all-cause mortality (top) and association between use of directly observed therapy and all-cause mortality (bottom). 
I year (log-rank test $p<0.00 \mathrm{I})$, as was the use of directly observed therapy (log-rank test $p<0.00 I)$.

Results from our Cox proportional hazards regression analyses are shown in Table 2. Our final multivariable model included 5 variables: age (in years) $(p<0.00 \mathrm{r})$, homelessness $(p=0.07)$, admission to hospital during the course of treatment ( $p<0.00 \mathrm{I})$, use of directly observed therapy $(p<0.00 \mathrm{I})$ and receipt of care from a physician experienced with tuberculosis (per case managed per year) $(p=0.0 \mathrm{I})$. Physician characteristics that were not associated with all-cause mortality on multivariable analysis included undergraduate medical training in a foreign country, postgraduate medical training and the total number of years in clinical practice.

\section{Interpretation}

Our study demonstrates that patient survival is influenced not only by patient characteristics, but also by features of the treating physician. It is frequently assumed that respirologists and infectious disease specialists are more capable than other physicians of managing cases of active tuberculosis. However, our analysis showed that patients managed by other physicians had similar survival rates to those of patients man-

Table 2: Risk factors influencing all-cause mortality among patients with active tuberculosis (TB) in Cox proportional hazards regression analyses

\begin{tabular}{|c|c|c|}
\hline Risk factor & $\begin{array}{c}\text { Crude HR } \\
(95 \% \mathrm{Cl})\end{array}$ & $\begin{array}{c}\text { Adjusted HR } \\
(95 \% \mathrm{Cl})^{*}\end{array}$ \\
\hline Age, yr & $1.06(1.05-1.07)$ & 1.05 (1.04-1.07) \\
\hline Homeless & $2.17(0.88-5.34)$ & $2.31(0.92-5.77)$ \\
\hline Admitted to hospital $†$ & $16.12(7.44-34.93)$ & $15.44(7.06-33.76)$ \\
\hline Received DOT† & $0.26(0.15-0.45)$ & $0.22(0.13-0.39)$ \\
\hline $\begin{array}{l}\text { Treating physician, } \\
\text { experience with TB (per } \\
\text { case managed per yr) }\end{array}$ & $0.98(0.97-1.00)$ & $0.98(0.97-0.99)$ \\
\hline Sex, female v. male & $0.63(0.40-0.98)$ & - \\
\hline Language, English & $0.36(0.23-0.55)$ & - \\
\hline HIV infection & $1.03(0.32-3.26)$ & - \\
\hline $\begin{array}{l}\text { High-risk site of } \\
\text { infection } \neq\end{array}$ & $3.53(1.54-8.12)$ & - \\
\hline Drug resistance (any)§ & $0.31(0.10-0.98)$ & - \\
\hline $\begin{array}{l}\text { Treating physician, } \\
\text { foreign graduate }\end{array}$ & $0.78(0.48-1.28)$ & - \\
\hline $\begin{array}{l}\text { Treating physician, } \\
\text { TB specialist** }\end{array}$ & $0.46(0.29-0.72)$ & - \\
\hline $\begin{array}{l}\text { Treating physician, } \\
\text { years in practice }\end{array}$ & $0.99(0.97-1.01)$ & - \\
\hline
\end{tabular}

Note: $\mathrm{HR}=$ hazard ratio, $\mathrm{Cl}$ = confidence interval, DOT = directly observed therapy. *Adjusted for age, homelessness, admission to hospital during course of TB treatment, receipt of DOT during course of TB treatment and management by physician experienced with TB.

†At any time during the course of TB treatment.

¥Site involving the cardiac or central nervous system.

§Organism was resistant to first-line TB drugs except streptomycin. Clinically

diagnosed cases and those with resistance to streptomycin alone were

considered nonresistant.

凡Completed undergraduate medical training outside of Canada.

${ }^{* *}$ Completed postgraduate training in respiratory medicine or infectious diseases. aged by respirologists or infectious disease specialists once tuberculosis experience had been accounted for. We also found a strong positive association between the use of directly observed therapy and survival.

Previous studies have shown that patient demographic characteristics, ${ }^{15,16}$ clinical factors ${ }^{17}$ and drug resistance ${ }^{17}$ are associated with increased mortality among tuberculosis patients. Although other studies have examined the relation between physician characteristics and tuberculosis treatment, they focused on more intermediate outcomes. ${ }^{9,10}$ Studies involving HIV/AIDS patients ${ }^{11,12}$ and patients undergoing specialized surgical procedures ${ }^{13,14}$ have shown a similar volume-outcome relation; however, many of these studies have been criticized for their inability to account for differences in patient case-mix. ${ }^{14,18,19}$ Previous randomized clinical trials comparing self-administered therapy and directly observed therapy administered by health care workers did not demonstrate a survival advantage. ${ }^{20-22}$ However, these studies were conducted in developing countries, and thus the findings may not be generalizable to urban settings in industrialized nations. ${ }^{23}$ A recent observational study in the United States identified a lower rate of death among patients receiving directly observed therapy than among those administering the therapy themselves; however, the study did not adjust for age and other important confounders. ${ }^{24}$

Our analysis is subject to the limitations of any observational study. Although we adjusted for an extensive number of patient and physician characteristics, there were certain factors that we were unable to account for. Our finding of an association between the use of directly observed therapy and patient survival is complicated by the fact that some of the patients in our cohort died during the same hospital stay in which their tuberculosis had been diagnosed. Since these patients were ineligible to receive directly observed therapy, we performed a subgroup analysis in which these patients were excluded and found that use of directly observed therapy was still associated with a decreased risk of death (HR 0.37, 95\% CI $0.20-0.67, p=0.001$ ). We used all-cause mortality as the primary outcome of our analysis because we had limited information on specific cause of death. Previous studies have cautioned against the use of cause-specific mortality because of the difficulties in ascertaining the specific cause of death and possible misclassification in death records. ${ }^{25-27}$ Although our analysis identified an association between physician experience with tuberculosis and patient survival, it is possible that the support of highly trained nursing staff, interpretation and other social services may have played an important role. We also considered that there may have been an association between the length of time a patient was known to have had tuberculosis (and to have survived) and the likelihood of referral to a tuberculosis-experienced physician. However, when we examined the relation between physician experience and patient duration of follow-up in the study, we found no evidence of a significant correlation (Pearson $r^{2}=0.02$ ). Nonetheless, our analysis remains limited in that it cannot conclusively speak to a causal relation between physician experience and patient survival. Ten patients were referred to another physician well into the course of their treatment (i.e., 
more than I month into therapy). A sensitivity analysis assigning these ro patients to either the referring or receiving physicians found no differences in our conclusions. Finally, we note that our measure of physician experience was limited to recent (i.e., within 3 years) management of tuberculosis cases in Toronto.

As tuberculosis incidence rates decline in Canada, the overall level of physician experience with this disease will decline. The findings of our analysis identify 2 modifiable factors that could potentially enhance treatment outcomes for tuberculosis patients in urban settings in industrialized countries: physician experience with tuberculosis and use of directly observed therapy. Thus, our findings advocate for a more structured system of tuberculosis case management that uses experienced physicians and directly observed therapy in routine patient care.

\section{This article has been peer reviewed.}

From the Centre for Research on Inner City Health and the Department of Medicine, Division of Infectious Diseases, St. Michael's Hospital, University of Toronto (Khan), the Infection Prevention and Control Unit, University Health Network (Campbell, Gardam) and Toronto Public Health (Wallington), Toronto, Ont.

Competing interests: None declared.

Contributors: Kamran Khan and Michael Gardam were each responsible for designing the study, directing the statistical analysis, interpreting the results and writing the manuscript. Ann Campbell collected and organized the data and contributed to the overall study design. Tamara Wallington contributed to the study design, interpreted the results and contributed to the final manuscript. All of the authors revised the manuscript for critical content and approved the final version.

Acknowledgements: We thank the Tuberculosis Prevention and Control Program staff at Toronto Public Health for their assistance with data collection and Jun Wang for programming and statistical support.

This study was supported by Physicians of Ontario through a Physician Services Incorporated research grant.

\section{REFERENCES}

I. Tuberculosis in Canada 200I. Ottawa: Health Canada; 2003. Available: www.phac -aspc.gc.ca/publicat/tbcanor/pdf/tbcan_200I_e.pdf (accessed 2006 June I4).

2. Trends in tuberculosis - United States, 1998-2003. MMWR Morb Mortal Wkly Rep 2004:53:209-I4.

3. Samaan G, Roche P, Spencer J, et al. Tuberculosis notification in Australia, 2002. Commun Dis Intell 2003;27:449-58.

4. Euro tuberculosis. Surveillance of tuberculosis in Europe, 2002. Available: www.eurotb.org/rapports/2002/report_2002.htm (accessed 2006 June I4).

5. Asch S, Leake B, Gelberg L. Does fear of immigration authorities deter tuberculosis patients from seeking care? West JMed I994;16r:373-6.
6. Carey JW, Oxtoby MJ, Nguyen LP, et al. Tuberculosis beliefs among recent Vietnamese refugees in New York State. Public Health Rep I997;II2:66-72.

7. Haddad MB, Wilson TW, Ijaz K, et al. Tuberculosis and homelessness in the United States, 1994-2003. JAMA 2005;293:2762-6.

8. Pablos-Mendez A, Knirsch CA, Barr RG, et al. Nonadherence in tuberculosis treatment: predictors and consequences in New York City. Am J Med 1997;102:I64-70.

9. Liu Z, Shilkret KL, Finelli L. Initial drug regimens for the treatment of tuberculosis: evaluation of physician prescribing practices in New Jersey, I994 to I995. Chest I998;II3:I446-5I.

Io. Rao SN, Mookerjee AL, Obasanjo OO, et al. Errors in the treatment of tuberculosis in Baltimore. Chest 2000;117:734-7.

II. Kitahata MM, Koepsell TD, Deyo RA, et al. Physicians' experience with the acquired immunodeficiency syndrome as a factor in patients' survival. $N$ Engl J Med I996;334:70I-6.

I2. Kitahata MM, Van Rompaey SE, Dillingham PW, et al. Primary care delivery is associated with greater physician experience and improved survival among persons with AIDS. J Gen Intern Med 2003;18:95-I03.

13. Birkmeyer JD, Stukel TA, Siewers AE, et al. Surgeon volume and operative mortality in the United States. N Engl J Med 2003;349:2117-27.

I4. Halm EA, Lee C, Chassin MR. Is volume related to outcome in health care? A systematic review and methodologic critique of the literature. Ann Intern Med 2002; I37:5II-20.

I5. World Health Organization (WHO). Global tuberculosis control - surveillance, planning and financing. Geneva: WHO; 2005. Available: www.who.int/tb/publications/global_report/2005/pdf/summary_eng.pdf (accessed 2006 June I4).

I6. Dye C, Watt CJ, Bleed DM, et al. Evolution of tuberculosis control and prospects for reducing tuberculosis incidence, prevalence, and deaths globally. JAMA 2005; 293:2767-75.

17. Pablos-Mendez A, Sterling TR, Frieden TR. The relationship between delayed or incomplete treatment and all-cause mortality in patients with tuberculosis. JAMA I996;276:1223-8.

I8. Panageas KS, Schrag D, Riedel E, et al. The effect of clustering of outcomes on the association of procedure volume and surgical outcomes. Ann Intern Med 2003; I39:658-65.

I9. Meyerhardt JA, Catalano PJ, Schrag D, et al. Association of hospital procedure volume and outcomes in patients with colon cancer at high risk for recurrence. Ann Intern Med 2003; I39:649-57.

20. Zwarenstein M, Schoeman JH, Vundule C, et al. Randomised controlled trial of self-supervised and directly observed treatment of tuberculosis. Lancet I998;352: I340-3.

2I. Kamolratanakul P, Sawert $\mathrm{H}$, Lertmaharit S, et al. Randomized controlled trial of directly observed treatment (DOT) for patients with pulmonary tuberculosis in Thailand. Trans R Soc Trop Med Hyg 1999;93:552-7.

22. Walley JD, Khan MA, Newell JN, et al. Effectiveness of the direct observation component of DOTS for tuberculosis: a randomised controlled trial in Pakistan. Lancet 2001;357:664-9.

23. Burman WJ, Reves RR. How much directly observed therapy is enough? Am J Respir Crit Care Med 2004;170:474-5.

24. Jasmer RM, Seaman CB, Gonzalez LC, et al. Tuberculosis treatment outcomes: directly observed therapy compared with self-administered therapy. Am J Respir Crit Care Med 2004; I70:56I-6.

25. Coady SA, Sorlie PD, Cooper LS, et al. Validation of death certificate diagnosis for coronary heart disease: the Atherosclerosis Risk in Communities (ARIC) Study. Clin Epidemiol 2001;54:40-50.

26. Myers KA, Farquhar DR. Improving the accuracy of death certification. CMAJ I 998 ; I58(10):1317-23.

27. Moussa MA, Shafie MZ, Khogali MM, et al. Reliability of death certificate diagnoses. J Clin Epidemiol 1990;43:1285-95.

Correspondence to: Dr. Michael Gardam, 200 Elizabeth St., Rm. $3 E S-428$, Toronto General Hospital, Toronto ON M5G $2 C_{4}$; fax 4I6 340-5047; michael.gardam@uhn.on.ca

\section{IMPACT}

$C M A J$ is a leading international general medical journal as ranked by Thomson ISI. 2005 impact factor, 7.4. 